\title{
Practical implications for nurses caring for patients being treated for osteoporosis
}

\author{
This article was published in the following Dove Press journal: \\ Nursing: Research and Reviews \\ 13 May 2014 \\ Number of times this article has been viewed
}

\author{
Suzanne C Smeltzer \\ Bing Bing Qi \\ Center for Nursing Research, College \\ of Nursing, Villanova University, \\ Villanova, PA, USA
}

\begin{abstract}
Osteoporosis is a major health problem throughout the world. Despite the serious consequences of osteoporosis and fractures, many people with low bone mass and those with osteoporosis are unaware of it, and as a result are not taking preventive actions and are receiving no treatment. Nurses have a major role in prevention, assessment, and teaching related to osteoporosis. This review presents what is currently known about osteoporosis and identifies specific activities that fall within the scope of nursing practice. Evidence-based recommendations are presented and summarized.
\end{abstract}

Keywords: nursing, osteoporosis, treatment, implications

\section{Introduction}

Osteoporosis, or porous bone, is the most common disease of bone and is characterized by low bone mass, deterioration of bone tissue, and compromised bone strength, leading to bone fragility and fractures. ${ }^{1,2}$ Osteoporosis may be due to too little bone formation or excessive bone loss..$^{3,4}$ When bone loss is mild or moderate, it is referred to as osteopenia. More severe bone loss is referred to as osteoporosis, and osteoporosis in the presence of one or more fragility fractures is referred to as severe osteoporosis. ${ }^{5}$ Osteoporosis can be categorized as primary or secondary. ${ }^{6-9}$

The most common sites of fracture are the hip, spine, and wrist. Although osteoporosis and fracture are commonly thought of as limited to post-menopausal women, such fractures also occur at an earlier age in women and in men as well. ${ }^{1}$ Osteoporosis can occur at younger ages in individuals who did not achieve optimal bone mass during childhood and adolescence for a variety of causes, eg, poor nutrition, underlying disease, prolonged immobility, and extreme exercise leading to amenorrhea. ${ }^{3,9}$

Osteoporosis is a major public health issue because of the personal consequences of fracture and its resulting economic burden. Osteoporosis can be prevented, detected, and treated. ${ }^{1}$ Equally important, treatment can prevent subsequent fractures after a first osteoporosis-related fracture occurs. ${ }^{8}$ Many of the measures needed to prevent or minimize bone loss and fracture are within the scope of practice of nurses, nurse practitioners, and nurse midwives.

This article presents an overview of information needed by nurses to provide effective care for people at risk of osteoporosis and those receiving treatment for it. In addition to review of key publications from authoritative bodies concerned with osteoporosis and its treatment, such as the National Osteoporosis Foundation ${ }^{8}$ and World Health Organization (WHO) ${ }^{5}$ an extensive review of databases (ProQuest,
Center for Nursing Research, College of Nursing, Villanova University, 800 Lancaster Avenue

Villanova, PA 19085, USA

Tel + I 6105196828

Email suzanne.smeltzer@villanova.edu
Nursing: Research and Reviews 2014:4 19-33

Dovepress

http://dx.doi.org/1 0.2147/NRR.S36648 (c) (i) (9) 2014 Smeltzer and Qi. This work is published by Dove Medical Press Limited, and licensed under Creative Commons Attribution - Non Commercial (unported, v3.0) BY LC License. The full terms of the License are available at http://creativecommons.org/licenses/by-nc/3.0/. Non-commercial uses of the work are permitted without any further hew to how to request permission may be found at: http://www.dovepress.com/permissions.php 
PubMed, Cochrane Database) was conducted to identify articles related to osteoporosis and implications for nursing practice.

\section{Epidemiology}

The International Osteoporosis Foundation ${ }^{10}$ estimates that osteoporosis affects over 200 million people worldwide, although there is considerable variation in hip fracture risk and fractures across regions of the world. The National Osteoporosis Foundation ${ }^{8}$ estimates that more than 10 million Americans have osteoporosis and an additional 33.6 million have low bone density at the hip. It is predicted that by 2050, the worldwide incidence of hip fracture in women will increase by $240 \%$ and by $310 \%$ in men. ${ }^{11}$ The majority of fractures occur in individuals with low bone mass (osteopenia) rather than osteoporosis, ${ }^{8,12}$ suggesting the need to address bone loss and prevention of fractures early rather than late in life. Although bone loss and osteoporosis occur in all races and ethnic groups, some populations (eg, Asians and Caucasians) are at higher risk than others because of genetic differences, smaller body frames than other groups, and low consumption of calcium in Asians because of lactose intolerance. ${ }^{13}$

Reduction in estrogen production that occurs with natural or early menopause (younger than 45 years of age) is a major contributor to osteoporosis in women. ${ }^{14}$ Although approximately $30 \%$ of post-menopausal women have osteoporosis, it also occurs in older men, typically at around the age of 70 years, ${ }^{15,16}$ and the mortality rate in men is double that in women of similar age. ${ }^{10}$ It has been estimated that one in every two women and one in every five men are at risk for fractures related to osteoporosis during their lifetime. ${ }^{10,17}$ Because of the importance of osteoporosis as a factor that affects the quality of life of a large number of people, the US Surgeon General's office issued its first report on bone health and osteoporosis in 2004. ${ }^{18}$

\section{Pathophysiology}

Osteoporosis is characterized by low bone mass or density and structural deterioration of bone tissue, leading to bone fragility and an increased risk of fractures of the hip, spine, wrist, and other bones. ${ }^{1,11}$ Bone density is determined by peak bone mass and the amount of bone loss. Peak bone mass refers to an individual's maximum bone density and strength. ${ }^{1,19,20}$

Bone is comprised of collagen and calcium phosphate. Collagen provides a flexible framework and calcium phosphate strengthens and hardens the framework. ${ }^{1}$ Changes in bone occur throughout the life span. As older bone is removed through resorption by osteoclasts, new bone is formed and added to the skeleton by osteoblasts. ${ }^{21}$ Hormonal factors that regulate mineral metabolism and mechanical loading on bone (as in weight-bearing exercise) along with local damage stimulate the process of remodeling. ${ }^{18}$ During childhood and adolescence, bone is added more rapidly than old bone is removed. As a result, during childhood, adolescence, and young adulthood, bones become heavier, larger, and denser. Peak bone mass is typically reached before 30 years of age. At that time, bone formation slows and eventually is exceeded by removal, or resorption, of bone. ${ }^{1}$ Greater resorption of bone without formation of new bone results in low bone density and increased risk for fractures. Factors that affect bone remodeling include hormonal influences, stress to the skeleton through load-bearing physical activities, and weightbearing exercise. In the absence of adequate amounts of mechanical loading and weight-bearing for sufficient periods, bone loss will occur. When the mechanical force produced by muscle is lost, as occurs in paralysis and immobilization, bone mass and strength are also rapidly lost. ${ }^{18}$

Although primary osteoporosis is common, secondary osteoporosis is also important. Secondary osteoporosis refers to osteoporosis that occurs as a result of other conditions or diseases or with the use of certain medications. ${ }^{6,7}$ It is characterized by bone loss greater than what would be expected for an unaffected individual of the same age, gender, and race. ${ }^{1,6,7}$ Causes include hypothyroidism, type 1 diabetes mellitus, malabsorption syndromes (eg, inflammatory bowel disease or following a gastric bypass), eating disorders (eg, anorexia nervosa), some genetic disorders (eg, cystic fibrosis), rheumatic and autoimmune disorders (eg, lupus, rheumatoid arthritis), and amenorrhea that occurs with extreme exercise. Other causes include high alcohol consumption, inadequate intake of calcium and vitamin D, lack of sun exposure, sedentary lifestyle, and lack of weightbearing exercise. Medications that have been implicated in bone loss include corticosteroids, anticoagulants, proton pump inhibitors, diuretics, lithium, anticonvulsants, thyroxin, and chemotherapeutic agents. ${ }^{6-8,22,23}$

\section{Consequences of osteoporosis}

Fractures are the most significant consequence of low bone mass and osteoporosis. ${ }^{18} \mathrm{~A}$ fracture occurs when a force such as trauma is applied to osteoporotic bone. Fractures due to osteoporosis, which are commonly referred to as fragility fractures when they occur with falls from a standing position or occur spontaneously, are likely to affect mobility, quality 
of life, morbidity, and mortality. The most common fractures are those of the vertebrae (spine), proximal femur (hip), and distal forearm (wrist). Although hip fractures account for less than $20 \%$ of osteoporosis fractures, ${ }^{24}$ they are associated with serious disability and mortality; only one third of patients who experience hip fracture regain their prefracture level of function, one third require nursing home placement, and one fifth are likely to die within one year. Additionally, hip fractures are followed by a 2.5 -fold increased risk of future fractures. ${ }^{8}$

Although the consequences of hip fracture are well known, less attention has been given to the effects of other types of osteoporotic fractures, including vertebral fractures, which often occur without an individual being aware of them. Such fractures can result in loss of height, kyphosis, and chronic back pain. Changes in posture associated with kyphosis may decrease an individual's participation in everyday activities, such as bending and reaching, and in usual social activities. ${ }^{8}$ Restrictive lung disease can be a consequence of multiple vertebral fractures in the thoracic region, leading to increased risks associated with respiratory function. Constipation, abdominal pain and distention, reduced appetite, and early satiety may occur with vertebral fractures in the lumbar area because of alterations in abdominal anatomy. ${ }^{8}$

Although wrist fractures are generally less disabling than hip and vertebral fractures, they can nevertheless interfere with activities of daily living. Fractures of the pelvis and proximal humerus (shoulder) are also associated with increased morbidity and mortality. ${ }^{8}$ Wrist fracture and loss of height due to vertebral fractures strongly suggest low bone mass, and should prompt referral of the patient for evaluation for bone loss. Further, the occurrence of one fracture is highly predictive of subsequent fractures. ${ }^{25,26}$

In addition to the loss of mobility, function, and independence, other quality of life issues include isolation and decreased social interaction with others, depression, loss of self-esteem due to changes in lifestyle and appearance, anxiety, fear, and anger. Although outcomes such as depression are frequently reported in women with established osteoporosis, they may be overlooked by health care providers despite their significance in the lives of those who experience them. ${ }^{27}$

The financial consequences of osteoporosis and fractures are daunting. Direct financial expenditures for treatment of osteoporotic fracture are estimated at \$10-\$15 USD billion annually. ${ }^{28-30} \mathrm{~A}$ majority of these costs are related to inpatient hospital care and do not include the costs of treatment for individuals without fractures, or the indirect costs of lost wages or productivity of either individuals with osteoporosis or their caregivers. Osteoporosis-related fractures create a heavy economic burden, causing more than 432,000 hospital admissions, almost 2.5 million medical office visits, and about 180,000 nursing home admissions annually in the USA. Although hip fractures account for $14 \%$ of osteoporotic fractures, they account for $72 \%$ of fracture costs. ${ }^{8}$

Osteoporosis is often ignored by health care providers, even when the individual has experienced a hip or other fracture with a high probability of it being due to bone loss and osteoporosis. ${ }^{12,31,32}$ Fewer than $20 \%$ of women with fractures likely due to low bone density are subsequently assessed for and treated for osteoporosis in the US and other countries. ${ }^{31-33}$ Equally important is that among patients who experience hip fracture, almost half have a history of previous bone fracture without subsequent follow-up or treatment. ${ }^{33}$ Lack of health care providers' attention to these issues strongly suggests the need to identify patients at increased risk for or with osteoporosis so that follow-up testing and treatment can be initiated. Assessment of risk factors is key to early detection and treatment.

\section{Risk factors for osteoporosis}

Many factors associated with osteoporosis cannot be modified, ie, gender, age, low body mass index, ethnicity, family history of osteoporosis and fractures, presence of some health conditions, and some medications essential for an individual's health and well-being. Other risk factors, however, can be identified and modified. ${ }^{22}$ These are summarized in Table 1, along with actions that can be recommended by nurses to patients. If medications that increase the risk of bone loss cannot be modified, other strategies (eg, calcium and vitamin $\mathrm{D}$ supplementation, weight bearing exercise, balance exercises) should be initiated to reduce the risk of osteoporosis, falls, and fractures. ${ }^{22,27}$

Because of the serious consequences of fracture due to low bone mass or osteoporosis described above, several assessment tools have been developed to assess the individual's risk for osteoporosis and fracture. It is recommended that patients be assessed using one of these assessment tools yearly., The Fracture Risk Assessment Tool (FRAX), developed by the $\mathrm{WHO}^{5}$ in 2008 (Geneva, Switzerland), is a computergenerated algorithm that provides an estimate of the risk for fracture in order to guide treatment decisions. An individual between 40 and 90 years of age is assessed for risk of major osteoporotic fracture in the next 10 years based on validated clinical risk factors and bone mineral density (BMD) test results if available. ${ }^{34-37}$ The clinical risk factors include age, 
Table I Modifiable osteoporosis risk factors and recommended actions

\begin{tabular}{lll}
\hline Risk factor & Description & Recommendations for patients \\
\hline Estrogen & Estrogen deficiency occurs with menopause and & Although estrogen replacement has been used in the past to \\
deficiency & results in rapid bone loss in women, contributing & prevent bone loss associated with menopause, increased risk for \\
& to $5 \%-10 \%$ loss of cortical bone and $20 \%-30 \%$ & breast cancer has resulted in this recommendation being rescinded. \\
& of trabecular bone. This is followed by a slower &
\end{tabular}

$\begin{array}{ll}\begin{array}{l}\text { Inadequate } \\ \text { calcium and }\end{array} & \begin{array}{l}\text { trabecular bone in both men and women. } \\ \text { vitamin D intake }\end{array} \\ \begin{array}{l}\text { increases the risk of bone loss. Many people fail } \\ \text { to consume even half of the calcium } \\ \text { recommended to build and maintain healthy } \\ \text { bones., }\end{array} \\ \text { Inactive life style } & \begin{array}{l}\text { An inactive or sedentary lifestyle or extended bed } \\ \text { rest tends to weaken bones because of lack of } \\ \text { adequate weight-bearing exercise. Activity-induced } \\ \text { loading promotes bone health. }\end{array}\end{array}$

Alcohol abuse

Smoking

Eating disorders
Some people are unable to increase their exercise because of pre-existing disabilities that limit their physical activity.

Excessive intake of alcohol may increase bone loss, including in young women and men. Alcohol abuse may increase risk because of poor nutrition and increased risk of falls may increase risk of fracture. Alcohol has been reported to inhibit bone remodeling. ${ }^{10}$

Women who smoke have lower levels of estrogen compared with nonsmokers, and may go through menopause earlier. Smoking may also interfere with absorption of dietary calcium. Toxins produced by smoking may impair the function of bone cells and decrease absorption of calcium from the intestine. ${ }^{8}$

Inadequate nutritional intake may increase risk because of inadequate consumption of foods with calcium and vitamin D and low body weight, which is an independent risk factor. 8,10
Increase dietary intake of calcium; take calcium and vitamin D supplements if dietary calcium intake is inadequate.

Modify calcium intake to correspond with recommendations for life stage.'

Avoid consumption of carbonated soft drinks in place of dairy products or foods fortified with calcium. ${ }^{1,8}$

Integrate weight-bearing exercise into daily activities: walking, hiking, jogging, climbing stairs, weight training, active sports. Strength-training (including weight lifting) or resistance-training activities produce the greatest benefit to bones. Exercises that include jumping are recommended for individuals without significant bone loss as jumping may increase risk of vertebral fractures. Participation in $\geq 30$ minutes of moderate physical activity on most (or all) days of the week is recommended. ${ }^{1,8}$

Consult a physical therapist or trainer for a program tailored to the individual. $^{8}$

Stop or limit alcohol intake to no more than I-2 ounces a day.,10

Stop smoking; employ smoking cessation strategies. ${ }^{1,8}$

Seek treatment for eating disorders. Ensure adequate caloric intake and consumption of foods with calcium and vitamin D. Use calcium and vitamin D supplementation if needed to achieve adequate intake. body mass index, history of fracture, high alcohol intake, smoking, and presence of rheumatoid arthritis or any other secondary causes of osteoporosis. QFracture ${ }^{\circledR}$ (ClinRisk Ltd., Leeds, UK) and FORE 10-Year Fracture Risk Calculator (Foundation for Osteoporosis Research and Education, Oakland, CA, USA) are other algorithms developed to predict the risk of osteoporotic fracture. ${ }^{38,39}$ The Male Osteoporosis Risk Estimation Score (MORES) ${ }^{40}$ is used to identify men 60 years and older who are at risk for osteoporosis and who should be referred for confirmatory diagnostic dual-energy $\mathrm{X}$-ray absorptiometry. MORES includes three variables, ie, age, weight, and history of chronic obstructive pulmonary disease. A MORES score of 6 or greater has been shown to have an overall sensitivity of $93 \%,{ }^{16,41}$ indicating that it predicts osteoporosis in men correctly $93 \%$ of the time. These fracture risk assessment tools are used to assess risk rather than to monitor treatment. Assessment of frailty in elderly patients with the Study of Osteoporosis index, which is based on weight loss, the subject's inability to rise from a chair five times without using the arms, and a reduced energy level, has been found to be useful in assessing risk for falls due to frailty. ${ }^{42}$

The Surgeon General's report ${ }^{18}$ on bone health identifies nurses as being in an ideal position to administer an osteoporosis risk factor assessment and to use the results to identify at-risk individuals. An important nursing role is the 
identification of those factors that increase a patient's risk for osteoporosis and for falls and discussion of strategies to address modifiable risk factors with the patient. Further, if a patient is identified as at increased risk for bone loss and osteoporosis based on assessment of risk factors, nurses are in a position to refer the patient to the primary care provider for appropriate follow-up testing and treatment. Diagnostic testing and treatments are discussed later in this paper.

\section{Diagnosis of osteoporosis}

Many people are unaware that they have low bone mass or osteoporosis until their first fragility (low-impact) fracture occurs. Measurement of BMD by dual-energy X-ray absorptiometry scan is used as a proxy for bone strength; BMD accounts for approximately $70 \%$ of bone strength. ${ }^{43}$ BMD test results reflect comparison of an individual's bone density with the ideal or peak bone density of a healthy 30-yearold adult. BMD is reported as a T-score, which reflects the standard deviation from the norm of a healthy young adult. Thus, T-scores of +1 to -1 are interpreted as normal bone density. Scores between -1 and -2.5 indicate low bone mass or osteopenia. Osteoporosis is defined by the WHO as T-scores of -2.5 and below. ${ }^{25}$ T-scores lower than -2.5 with one or more osteoporotic fractures are indicative of severe osteoporosis. ${ }^{5}$ T-scores and their interpretation are summarized in Table 2. Z-scores are also reported and reflect comparison of a patient's BMD with an age-matched and gender-matched sample. Because low BMD is common in older adults, the Z-score can be misleading and is less valuable than the T-score. ${ }^{44}$

Although BMD scores are used widely, controversy exists about the BMD T-score of -2.5 or below as a criterion for

Table 2 World Health Organization definitions based on bone density levels

\begin{tabular}{|c|c|}
\hline Level & Definition/interpretation \\
\hline Normal & $\begin{array}{l}\text { Bone density is within I SD }( \pm I) \text { of the young } \\
\text { adult mean. }\end{array}$ \\
\hline $\begin{array}{l}\text { Low bone mass } \\
\text { (osteopenia) }\end{array}$ & $\begin{array}{l}\text { Bone density is between I and } 2.5 \mathrm{SD} \text { below } \\
\text { the young adult mean ( }-\mathrm{I} \text { to }-2.5 \mathrm{SD}) \text {. Often } \\
\text { interpreted as osteopenia. }\end{array}$ \\
\hline Osteoporosis & $\begin{array}{l}\text { Bone density is } 2.5 \mathrm{SD} \text { or more below the young } \\
\text { adult mean ( }-2.5 \mathrm{SD} \text { or lower). }\end{array}$ \\
\hline $\begin{array}{l}\text { Severe (established) } \\
\text { osteoporosis }\end{array}$ & $\begin{array}{l}\text { Bone density is more than } 2.5 \text { SD below the } \\
\text { young adult mean, and there have been one or } \\
\text { more osteoporotic fractures. }\end{array}$ \\
\hline
\end{tabular}

Note: Reproduced with the permission of the publisher, from Assessment of osteoporosis at the primary health care level. Geneva, World Health Organisation, 2007 (WHO Scientific Group Technical Report; http://www.iofbonehealth.org/sites/ default/files/WHO_Technical_Report-2007.pdf, accessed May 12 2014). ${ }^{5}$

Abbreviation: SD, standard deviation. osteoporosis and as a threshold for treatment. Further, it is not known if this is an appropriate diagnostic criterion for men, children, and across ethnic groups. The $\mathrm{WHO}^{25}$ emphasizes the need to consider other factors in addition to T-scores when determining need for treatment of low bone density. It is important to note that research has demonstrated that BMD test results obtained one year before a fracture occurred were not diagnostic of osteoporosis in a cohort of 149,524 white post-menopausal women aged 50-104 years recruited from primary care practices in the USA. In fact, only $18 \%$ of women who experienced fractures of the wrist or forearm, hip, rib, or spine met the threshold of -2.5 for treatment. ${ }^{12}$ Thus, the results of BMD testing need to be interpreted with caution.

The recommendations for testing for low bone density and osteoporosis have changed over time and differ slightly between organizations making recommendations. ${ }^{8,14,17}$ The National Osteoporosis Foundation ${ }^{8}$ recommends BMD testing for all women 65 years of age and older and postmenopausal women under 65 years of age, based on their risk factor profile as well as all men 70 years of age and older and men aged between 50 and 69 years of age who are at risk for osteoporosis. An expert panel convened by the National Institutes of $\mathrm{Health}^{2}$ in 2000 recommended BMD testing for people taking corticosteroids for 2 or more months and those at high risk for osteoporosis fractures. BMD should be tested no more frequently than every 2 years. ${ }^{41}$

Although the majority of cases of osteoporosis are considered primary and related to decreased estrogen production in women with menopause and aging in both men and women, testing for causes of secondary osteoporosis may be indicated because the treatment of secondary osteoporosis differs from that of primary osteoporosis, and usually involves treatment of the causes of secondary osteoporosis. Laboratory tests that may be used for initial evaluation of a patient for osteoporosis and for diagnosis of secondary osteoporosis are identified in Table 3.

\section{Treatment of low bone mass/ osteoporosis}

Treatment of patients with low bone mass or osteoporosis includes both pharmacologic and nonpharmacologic approaches. Both approaches have implications for nurses, including ensuring that patients are knowledgeable about the medications that are prescribed and their correct administration to ensure that they are as effective as possible, as well as instructing them about the nonpharmacologic management of low bone mass or osteoporosis. Nonpharmacologic 
Table 3 Selected diagnostic tests used to identify causes of primary and secondary osteoporosis

\begin{tabular}{|c|c|}
\hline Tests & Rationale for tests \\
\hline \multicolumn{2}{|l|}{ Chemistry levels } \\
\hline - Alkaline phosphatase & - Used to identify effects of immobilization, Paget's disease, acute fractures, other bone diseases \\
\hline - Calcium & $\begin{array}{l}\text { - Measured prior to initiation of medications; also obtained to rule out hypocalcemia (due to malabsorption } \\
\text { syndromes and vitamin D deficiency) and hypercalcemia due to hyperparathyroidism }\end{array}$ \\
\hline - Liver or kidney function tests & - Obtained to identify liver or kidney disease, which may be underlying cause \\
\hline Complete blood count & - Used to rule out bone marrow malignancy, malabsorption syndromes, or infiltrative process (anemia) \\
\hline Thyroid-stimulating hormone & - Used to diagnosis hyperthyroidism; also obtained in patients on thyroid hormone supplementation \\
\hline Parathyroid hormone & - Used to rule out hyperparathyroidism \\
\hline Total testosterone level (men) & - Used to exclude hypogonadism as underlying cause \\
\hline \multicolumn{2}{|l|}{ Estradiol (women) } \\
\hline 25-hydroxyvitamin D & $\begin{array}{l}\text { - Used to identify vitamin D deficiency, which should be corrected prior to initiation of treatment of low bone } \\
\text { mass or osteoporosis } \\
\text { - Also used to rule out hyperparathyroidism as cause of secondary osteoporosis }\end{array}$ \\
\hline 24-hour urinary calcium & $\begin{array}{l}\text { - Used to identify malabsorptive states (such as celiac sprue) or vitamin D deficiency. Identifies hypercalciuria } \\
\text { (which is a correctable cause of bone loss) }\end{array}$ \\
\hline $\begin{array}{l}\text { Biochemical markers of } \\
\text { bone turnover }\end{array}$ & $\begin{array}{l}\text { - May be obtained in selected patients to assess bone turnover. Markers include serum C-telopeptide, serum } \\
\text { bone-specific alkaline phosphatase, osteocalcin, and amino terminal propeptide of type I procollagen. Urine } \\
\text { tests may include N-telopeptide }\end{array}$ \\
\hline Lateral chest X-rays & - Anterior-posterior X-rays of the thorax may be used to identify vertebral fractures as a cause of loss of height \\
\hline
\end{tabular}

Note: Data from Premaor and Compston, ${ }^{6}$ Hofbauer et $\mathrm{al}^{7}$ and the National Osteoporosis Foundation. ${ }^{8}$

intervention includes modification of general lifestyle factors, such as a healthy diet containing calcium and vitamin D, participation in weight-bearing exercise and exercises that enhance strength and balance, and avoidance of smoking and high alcohol consumption (see Table 4).

\section{Nurses' role in osteoporosis}

Patients with osteoporosis or low bone mass are generally treated, if they are diagnosed and treated at all, in outpatient settings. However, because of the high prevalence of osteoporosis, many hospitalized patients are likely to have low bone mass or osteoporosis but are often unaware of it and are often untreated. Several studies have demonstrated that more than $80 \%$ of older patients with new fractures, including hip fracture, do not receive treatment for osteoporosis despite the strong likelihood that the fractures are due to low bone mass, the wide availability of effective medications, and the likelihood of future fractures in both men and women. ${ }^{31-33}$ A recent study revealed that $64.3 \%$ of 65,344 women aged 55 years and older from a US managed care population received no pharmacologic treatment within one year after receiving a diagnosis of osteoporosis. ${ }^{31}$ Research has also shown that long-term care residents, most of whom are at high risk for osteoporosis and falls, do not receive the recommended assessments of risk factors or BMD. As a result, undertreatment and lack of treatment are common. ${ }^{45}$ Inadequate attention to detection and treatment of osteoporosis presents an opportunity for hospital-based nurses and those in long-term care facilities to address the issue.
In an effort to address the gap in management of osteoporosis in high-risk hospitalized patients, bone health teams, also referred to as fracture follow-up teams or fracture liaison services, consisting of members of a variety of health care professionals, are being implemented to raise awareness among health care providers about osteoporosis, ensure that patients are assessed for risk of low bone density and risk of fracture, and provide preventive and therapeutic management of osteoporosis. ${ }^{46-49}$ Again, nurses are key to the success of these interdisciplinary efforts. They are positioned to take the lead in addressing this issue by assessing bone health and osteoporosis risk factors in all age groups and in all settings in which they interact with patients.

The role of nurses in caring for patients with osteoporosis or at risk for osteoporosis, regardless of setting, includes enhancing patients' knowledge about osteoporosis and promoting behavior change. Specific nursing actions include: providing patient education across the lifespan about bone health and prevention of osteoporosis and fractures, including discussing strategies to ensure bone health in adolescents as well as young adults and older patients; $;{ }^{14}$ assessing patients' risk for low bone density or osteoporosis; providing education to patients with or at risk of osteoporosis and their families about pharmacologic and nonpharmacologic treatment strategies; educating patients and their family caregivers about the risk for falling and strategies to prevent falls at home; assessing the risk factors for falls and implementing strategies during a patient's hospitalization to decrease the risk of falls and fracture in those with or at risk for osteoporosis; providing nursing care for patients at risk for 


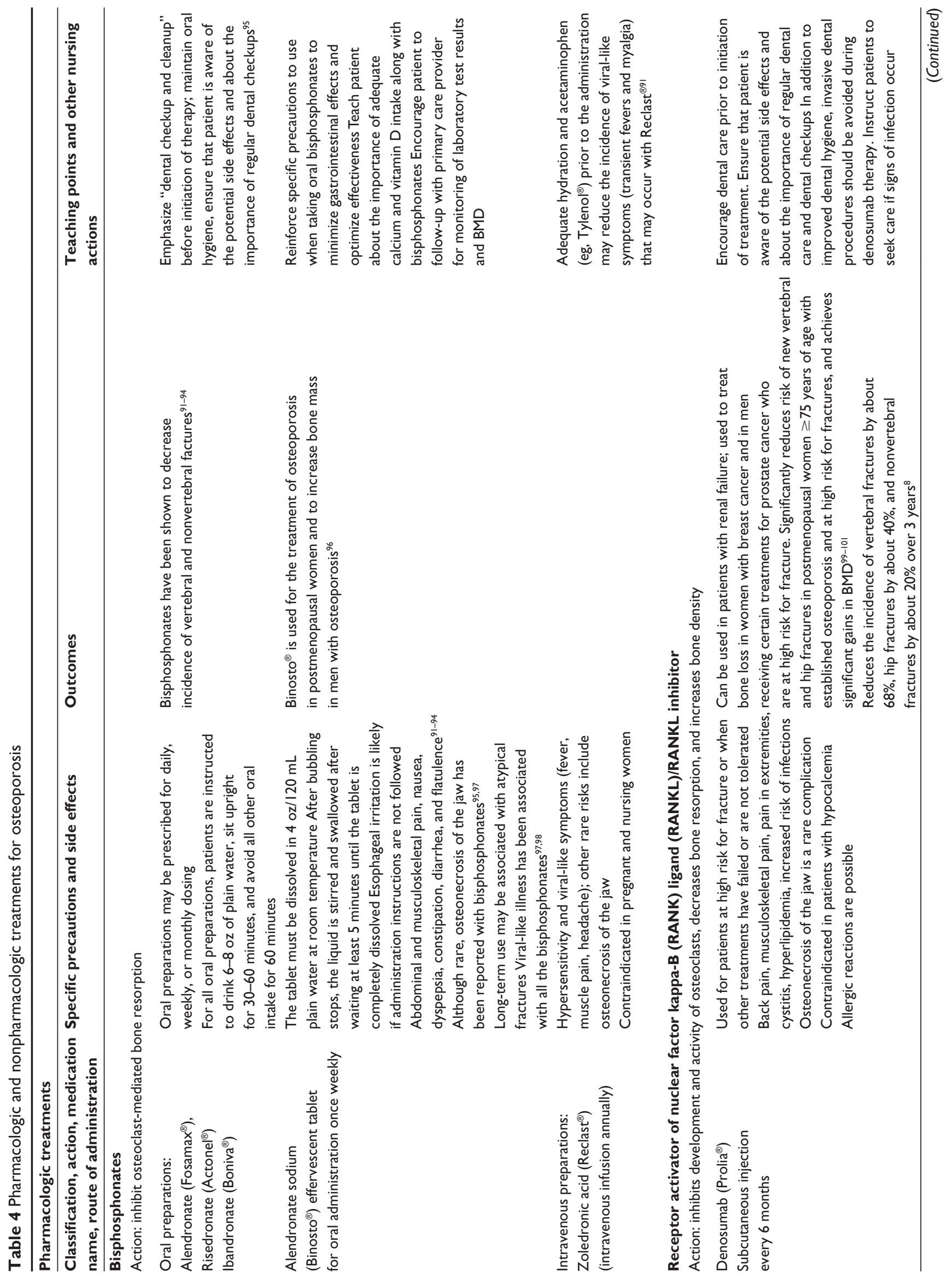




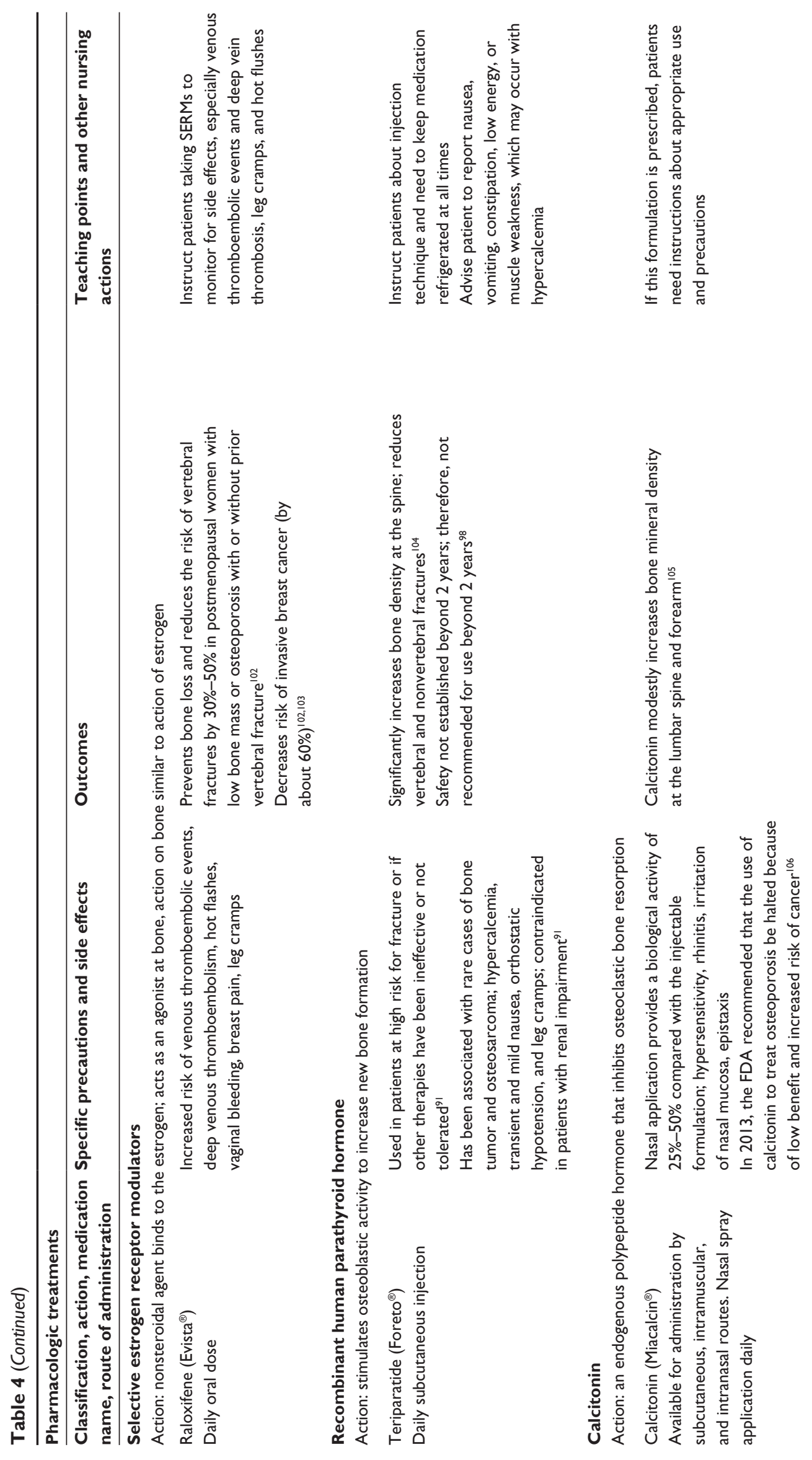




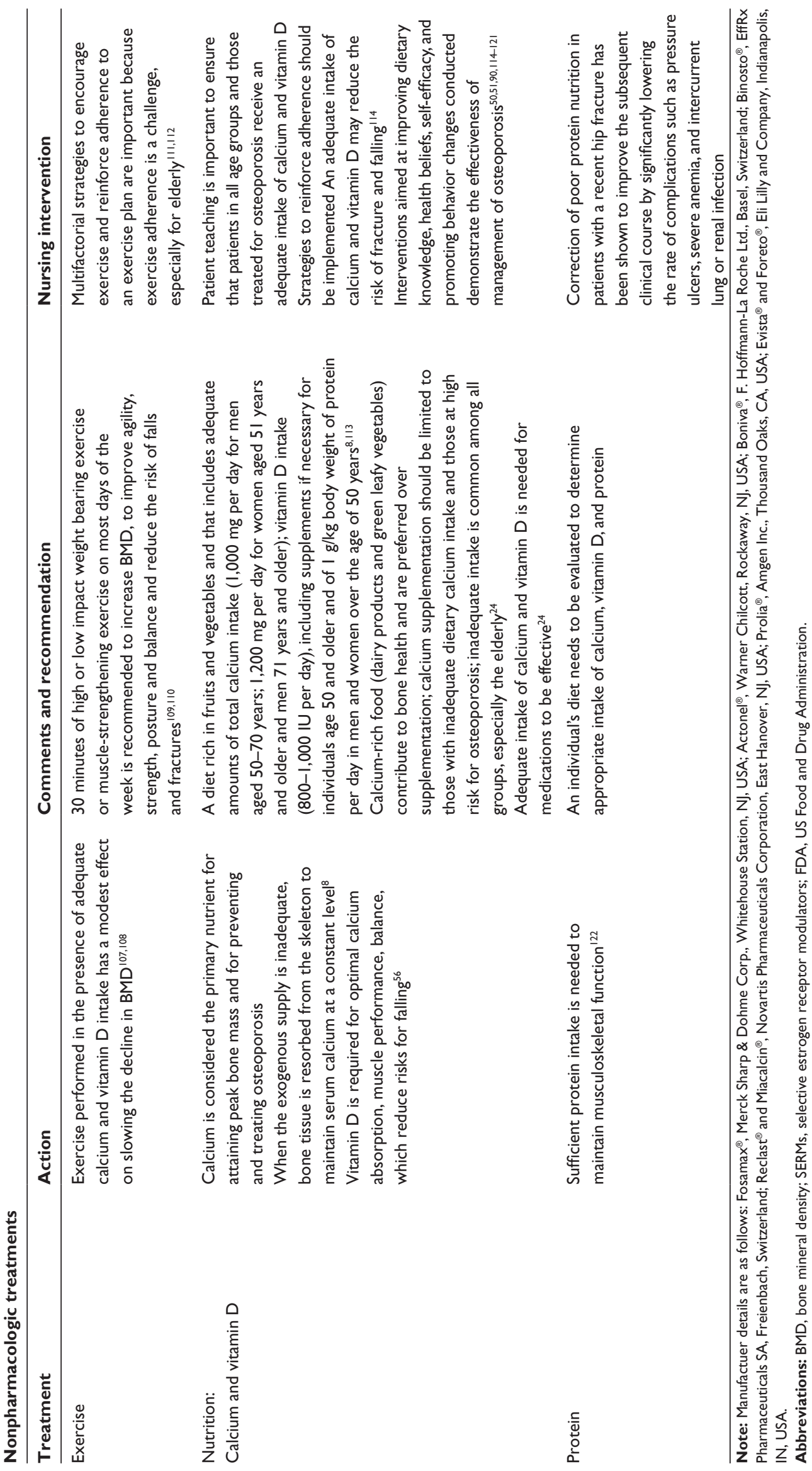


complications of osteoporosis; and promoting adherence to medication and lifestyle changes.

\section{Enhancing patients' knowledge}

Many interventional studies have shown that enhanced knowledge encourages patients to seek additional information about osteoporosis and leads to lifestyle changes. ${ }^{50-53}$ Studies conducted in the USA and other countries have shown a low level of knowledge about osteoporosis among general groups of women and men and those at increased risk for osteoporosis because of age, having first-degree relatives with osteoporosis or fracture, having a disability, or receiving chemotherapeutic agents or other medications that negatively affect bone density or other risk factors. ${ }^{54-62}$ Research has shown that although participants may have good knowledge of what osteoporosis is, they generally have a low level of understanding of the role of medication in reducing fracture risk, various concerns about the side effects of medication, poor understanding of the causes of osteoporosis, and uncertainty about how it can be controlled. ${ }^{63}$

Demographic and social factors have been linked to a low level of knowledge about osteoporosis. Studies have found that being male, having English as a second language, and not exercising are associated with a lower level of knowledge. ${ }^{51}$ Prior studies have also shown that those who are unemployed or have a lower income are at greater risk for osteoporosis and low-impact fractures. ${ }^{64,65}$ These findings may reflect a lack of opportunity to participate in behaviors known to affect bone health. Although men have a high mortality rate after sustaining a low-impact fracture, ${ }^{66}$ most osteoporosis educational efforts up to this point target women and are delivered in English. The findings of these studies suggest the need to target educational interventions to men, those with low income, those who are unemployed, and groups in which English is not the primary language to reduce the risk of future fractures in these highrisk groups. ${ }^{67}$ Studies are needed to evaluate the effectiveness of such interventions in these populations.

Some osteoporosis education materials have been translated literally to reach those who do not speak English or those for whom English is a second language. However, there may be issues with cultural translation that limit the understanding and applicability of the information provided for these populations. ${ }^{67}$ Therefore, nurses need to tailor their educational interventions to the culture, language, and needs of specific ethnic groups.

In providing information about osteoporosis to patients, including explanations of what osteoporosis is, its consequences, and the factors that increase its likelihood and the risk for falls, nurses need to have an adequate breadth and depth of knowledge about osteoporosis and its treatment. Research, however, has demonstrated inadequate knowledge about osteoporosis among nursing students in the final year of their nursing education and prior to their clinical internship. ${ }^{68,69}$ In order to provide accurate information about medications prescribed to treat osteoporosis, nurses must also be knowledgeable about the correct method of administration. Although bisphosphonates have been shown to be effective in increasing BMD and reducing the risk for fractures, these medications are effective only when administered correctly. A recent study ${ }^{70}$ demonstrated that in a sample of nurses and patient support workers from long-term care facilities, only $52 \%$ of the nurses and $8.7 \%$ of the patient support workers responsible for administration of medications administered bisphosphonates correctly (ie, gave the medication before meals, with water, separated from all other medications, with the patient in an upright position for at least 30 minutes).

\section{Strengthening patients' health beliefs and promoting behavior change}

Studies have shown that appropriate pharmaceutical care improved osteoporosis-related knowledge, quality of life, and satisfaction in post-menopausal osteoporotic women. ${ }^{70}$ Pharmaceutical care includes a medication review, education on osteoporosis, risk factors, lifestyle modifications, goals of therapy, side effects, and the importance of medication adherence ${ }^{70}$ Despite the efficacy of treatments in reducing fracture risk, poor adherence among patients is a problem in osteoporosis. ${ }^{71}$ Factors that influence health behaviors related to osteoporosis include lack of knowledge related to osteoporosis, lack of belief in the benefits associated with prevention, lack of motivation to overcome barriers to osteoporosis prevention, lack of social support, inadequate access to care and behavior change opportunities, and language barriers. The majority of the successful interventions involved more than one type of intervention (eg, education combined with selfmanagement) and use of strategies for engaging patients to influence their health beliefs and attitudes about osteoporosis and recommended medications. ${ }^{72,73}$ Many studies have demonstrated that health beliefs or self-efficacy play an important role in adoption and maintenance of healthy behaviors for osteoporosis prevention and treatment adherence. ${ }^{51,74,75}$

Studies have shown that both self-efficacy and outcome expectations play an important role in exercise, dietary behaviors, and medication adherence in adults..$^{50,51,76-78}$ Nurses can apply these intervention strategies in practice to promote behavior changes. ${ }^{58,79-81}$ Nurses can be part of the efforts to 
prevent second fractures in patients who have experienced a first fracture. ${ }^{46-49}$

Research $^{51,58,62,82-87}$ has demonstrated that well planned and executed theory-based educational interventions can be effective in increasing consumption of foods rich in calcium and vitamin $\mathrm{D}$ or use of supplements, increasing participation in exercise, increasing BMD testing, and modifying other lifestyle behaviors that increase the risk for bone loss. However, few patients receive adequate education unless they are

Table 5 Falls prevention

Outdoors (patient education)

- Use a cane or walker for added stability

- Wear rubber-soled shoes for traction

- Use ice cleats to avoid slipping on ice and falling

- Walk on grass when sidewalks are slippery

- In winter, carry salt or kitty litter to sprinkle on slippery sidewalks

- Be careful on highly polished floors that become slick and dangerous when wet

- Use plastic or carpet runners when possible

Indoors (patient education)

- Keep rooms free of clutter, especially floors

- Keep floor surfaces smooth but not slippery

- Wear supportive, low-heeled shoes even at home

- Avoid walking in socks, stockings, or slippers

- Be sure carpets and area rugs have skid-proof backing or are tacked to the floor

- Be sure stairwells are well lit and that stairs have handrails on both sides

- Install grab bars on bathroom walls near tub, shower, and toilet

- Use a rubber bath mat in shower or tub

- Keep a flashlight with fresh batteries beside the bed to use when getting up in the dark; use a night light

- If using a step stool for hard-to-reach areas (avoid their use if possible), use a sturdy one with a handrail and wide steps

- Add ceiling fixtures to rooms lit by lamps to avoid shadows

- Consider purchasing a cordless phone so that there is no rush to answer the phone when it rings, or so that you can call for help if you do fall

- Engage in activities to improve strength and balance (eg, muscle strengthening exercises, Tai Chi)

- Keep closet doors and drawers closed

If patient is hospitalized (nursing actions)

- Encourage patient to use assistive device if used at home

- Have patient's shoes readily available and encourage patient to wear them rather than slippers when out of bed

- Keep bed in a low position to make it easier for the patient to get out of bed safely

- Avoid full length side rails on bed

- Maintain adequate light in the patient's room at all times, including at night

- Remove objects (eg, chairs, tables) in the patient's room that serve as barriers to the bathroom

- Ensure that any spills are cleaned up immediately to prevent patient from slipping and falling

- Keep call-bell within easy reach of patient at all times

- Place all objects that may be needed by the patient within easy reach participants in research studies. Information developed for the public and guidelines for assessing and treating patients with osteoporosis are available from many agencies and organizations, such as the National Institutes of Health and the National Osteoporosis Foundation, ${ }^{1-3,8}$ and can be used effectively to introduce the topic to patients and to follow up accordingly.

Another major challenge is that many patients with osteoporosis take their prescription medications incorrectly, infrequently or not at all, delay obtaining their medications, or take them in the wrong dosage or at the wrong time. ${ }^{88}$ Poor compliance with osteoporosis treatment and resistance to use of osteoporosis medications significantly lower treatment-related outcomes, including slowed bone loss in elderly patients, and result in large groups of patients being untreated. As a result, the public health objective to reduce fractures is not met. The role of nurses in improving adherence and persistence includes understanding the factors that affect nonadherence, monitoring the effects and side effects of medication, and identifying patients who are at high risk of poor adherence over time. ${ }^{36,71,88}$ Studies are needed to identify strategies for improving adherence with medication regimens, recommending BMD testing, and improving lifestyle behaviors over time.

Research has shown that although patient education is necessary to effect behavior change, it is not sufficient. ${ }^{89}$ If patients undergo BMD testing and have the results explained to them, they are more likely to take measures to reduce their risks, such as increasing their intake of calcium and vitamin $\mathrm{D}$, than patients who do not undergo BMD testing. ${ }^{90}$ Thus, encouraging patients to undergo BMD testing and interpreting their BMD scores to them may increase the likelihood that they will follow the treatment plan and comply with recommendations for medications and lifestyle changes.

In addition to educating patients about osteoporosis and risk factors for bone loss, nurses also need to focus on prevention of falls in those at risk. Several specific approaches have demonstrated benefits, including muscle strengthening and balance retraining, professional home hazard assessment and modification, vision check, and medication review. Nurses need to take responsibility for monitoring patients' arrays of medications to identify those that affect bone health or increase the risk of falls. Nurses then need to bring these medications to the attention of the patient's primary care provider to determine if all are needed or others with less potential to cause bone loss can be substituted, along with the need for supplemental calcium and vitamin D if warranted. 
Table 5 identifies specific strategies designed to reduce the risk for falls.

\section{Conclusion}

The number of people with low bone mass or osteoporosis around the world is high and increasing rapidly with the aging of the population. Many people are unaware that they are at risk for developing osteoporosis or already have it. Prevention of bone loss and falls is a major goal that if implemented will prevent fractures, decrease morbidity related to fractures, improve quality of life, and reduce mortality. Nurses who are knowledgeable about osteoporosis and its prevention are in a key position to make a significant difference to the quality of life of people who might otherwise experience life-threatening fractures, disability, and premature death. As stated earlier, many measures needed to prevent or minimize bone loss are within the scope of nursing. All patients deserve to learn about the often preventable risks of osteoporosis so that they can live their lives with the quality of life they desire.

\section{Disclosure}

The authors report no conflicts of interest in this work.

\section{References}

1. National Institutes of Health Osteoporosis and Related Bone Diseases National Resource Center. Osteoporosis overview. January, 2012. Available from: http://www.niams.nih.gov/Health_Info/Bone/ Osteoporosis/overview.asp. Accessed February 4, 2014

2. National Institutes of Health Osteoporosis and Related Bone Diseases National Resource Center. Osteoporosis prevention, diagnosis, and therapy. NIH Consensus Statement 2000. Available from: http://www. ncbi.nlm.nih.gov/pubmed/11176917. Accessed February 4, 2014.

3. National Institutes of Health Osteoporosis and Related Bone Diseases National Resource Center. Juvenile osteoporosis. January, 2012. Available from: http://www.niams.nih.gov/Health_Info/Bone/Bone_ Health/Juvenile/juvenile_osteoporosis.asp. Accessed February 4, 2014.

4. Bianchi ML. Osteoporosis in children and adolescents. Bone. 2007:41:486-495.

5. World Health Organization. Assessment of osteoporosis at the primary health care level. Summary Report of a WHO Scientific Group. Geneva, Switzerland; World Health Organization; 2007. Available from: www. who.int/chp/topics/rheumatic/. Accessed February 4, 2014.

6. Premaor MO, Compston JE. Testing for secondary causes of osteoporosis. BMJ. 2010;341:c6959.

7. Hofbauer LC, Hamann C, Ebeling PR. Approach to the patient with secondary osteoporosis. Eur J Endocrinol. 2010;162:1009-1020.

8. National Osteoporosis Foundation. Clinician's guide to prevention and treatment of osteoporosis. Washington, DC, USA: National Osteoporosis Foundation. 2013. Available from: http://nof.org/hcp/cliniciansguide. Accessed February 4, 2014.

9. Bianchi ML. Causes of secondary pediatric osteoporosis. Pediatr Endocrinol Rev. 2013;10 Suppl 2:424-436.

10. International Osteoporosis Foundation. Bone care for the postmenopausal woman. Nyon, Switzerland: International Osteoporosis Foundation; 2013. Available from: http://www.iofbonehealth.org/ data-publications/reports/bone-care-postmenopausal-woman. Accessed February 4, 2014.
11. Kanis JA, Odén A, McCloskey EV, Johansson H, Wahl DA, Cooper C; IOF Working Group on Epidemiology and Quality of Life. A systematic review of hip fracture incidence and probability of fracture worldwide. Osteoporos Int. 2012;23:2239-2256.

12. Siris ES, Chen YT, Abbott TA, et al. Bone mineral density thresholds for pharmacological intervention to prevent fractures. Arch Intern Med. 2004;164:1108-1112.

13. National Institutes of Health Osteoporosis and Related Bone Diseases National Resource Center. Osteoporosis and Asian American women. Jan 2012. Available from: http://www.niams.nih.gov/Health_Info/ Bone/Osteoporosis/Background/asian_american_women.asp. Accessed February 4, 2014.

14. American College of Obstetricians and Gynecologists. Committee on Practice Bulletins-Gynecology. Practice Bulletin \#129. Osteoporosis. Obstet Gynecol. 2012;120:718-734.

15. Johnell O, Kanis J. Epidemiology of osteoporotic fractures. Osteoporos Int. 2005;16 Supp1 2:S3-S7.

16. Rao SS, Budhwar N, Ashfaque A. Osteoporosis in men. Am Fam Physician. 2010;82:503-508.

17. US Preventive Services Task Force. Screening for osteoporosis: US Preventive Services Task Force recommendation statement. Ann Intern Med. 2011;154:356-364.

18. US Department of Health and Human Services. Bone Health and Osteoporosis: A Report of the Surgeon General. Rockville, MD: US Department of Health and Human Services, Office of the Surgeon General; 2004.

19. Licata A. Bone density vs bone quality: what's a clinician to do? Cleve Clin J Med. 2009;76:331-336.

20. Seeman E, Delmas PD. Bone quality - the material and structural basis of bone strength and fragility. N Engl J Med. 2006;354:2250-2261.

21. Lerner UH. Osteoblasts, osteoclasts, and osteocytes: unveiling their intimate-associated responses to applied orthodontic forces. Semin Orthod. 2012;18:237-248.

22. Sandhu SK, Hampson G. The pathogenesis, diagnosis, investigation and management of osteoporosis. J Clin Pathol. 2011;64:1042-1050.

23. Davidge Pitts CJ, Kearns AE. Update on medications with adverse skeletal effects. Mayo Clin Proc. 2011;86:338-343.

24. Ström O, Borgstrom F, Kanis JA, et al. Osteoporosis: burden, health care provision and opportunities in the EU. A report prepared in collaboration with the International Osteoporosis Foundation (IOF) and the European Federation of Pharmaceutical Industry Associations (EFPIA). Arch Osteoporos. 2011;6:59-155.

25. Florence R, Allen S, Benedict L, et al. Institute for Clinical Systems Improvement. Diagnosis and Treatment of Osteoporosis. Updated Jul 2013. Available from: https://www.icsi.org/_asset/vnw0c3/OsteoInteractive0711.pdf. Accessed February 14, 2014.

26. Adachi JD, Adami S, Gehlbach S, et al. Impact of prevalent fractures on quality of life: baseline results from the Global Longitudinal Study of Osteoporosis in Women. Mayo Clin Proc. 2010;85:806-813.

27. Rizzoli R, Brandi ML, Dreinhöfer KE, Thomas T, Wahl DA, Cooper C. The gaps between patient and physician understanding of the emotional and physical impact of osteoporosis. Arch Osteoporos. 2010;5:145-153.

28. Burge R, Dawson-Hughes B, Solomon DH, Wong JB, King A, Tosteson A. Incidence and economic burden of osteoporosis-related fractures in the United States, 2005-2025. J Bone Miner Res. 2007;22:465-475.

29. Cauley JA. Public health impact of osteoporosis. J Gerontol A Biol Sci. 2013;68:1243-1251.

30. Tosteson AN, Melton LJ 3rd, Dawson-Hughes B, et al; National Osteoporosis Foundation Guide Committee. Cost-effective osteoporosis treatment thresholds: the United States perspective. Osteoporos Int. 2008; 19:437-447.

31. Siris ES, Modi A, Tang J, Gandhi S, Sen S. Substantial undertreatment among women diagnosed with osteoporosis in a US managed-care population: a retrospective analysis. Curr Med Res Opin. 2014;30:123-130. 
32. Greenspan SL, Wyman A, Hooven FH, et al. Predictors of treatment with osteoporosis medications after recent fragility fractures in a multinational cohort of postmenopausal women. J Am Geriatr Soc. 2012;60:455-461.

33. Port L, Center J, Briffa NK, Nguyen T, Cumming R, Eisman J. Osteoporotic fracture: missed opportunity for intervention. Osteoporos Int. 3003;14:780-784.

34. Sosa M, Gonzalez-Padila E. Promising developments in osteoporosis treatment. Int J Clin Rheumatol. 2011;6:325-332.

35. Hans DB, Kanis JA, Baim S, et al; FRAX ${ }^{\circledR}$ Position Development Conference Members. Joint Official Positions of the International Society for Clinical Densitometry and International Osteoporosis Foundation on FRAX ${ }^{\circledR}$. Executive Summary of the 2010 Position Development Conference on Interpretation and use of FRAX ${ }^{\circledR}$ in clinical practice. J Clin Densitom. 2011;14:171-180.

36. Kanis JA, Hans D, Cooper C, et al. Task Force of the FRAX Initiative. Interpretation and use of FRAX in clinical practice. Osteoporos Int. 2011;22:2395-2411.

37. Unnanuntana A, Gladnick BP, Donnelly E, Lane JM. The assessment of fracture risk. J Bone Joint Surg Am. 2010;92:743-753.

38. Hippisley-Cox J, Coupland C. Derivation and validation of updated QFracture algorithm to predict risk of osteoporotic fracture in primary care in the United Kingdom: prospective open cohort study. $B M J$ 2012;344:e3427.

39. Ettinger B, Blackwell T, Hoffman AR, Ensrud KE, Orwoll ES; Osteoporotic Fracture in Men (MrOS) Research Group. Validation of FRC, a fracture risk assessment tool, in a cohort of older men: the Osteoporotic Fractures in Men (MrOS) Study. J Clin Densitom. 2012;15: 334-342.

40. Shepherd AJ, Cass AR, Carlson CA, Ray L. Development and internal validation of the male osteoporosis risk estimation score. Ann Fam Med. 2007;5:540-546.

41. National Guideline Clearinghouse. Guideline synthesis: Screening and risk assessment for osteoporosis. In: National Guideline Clearinghouse. Rockville, MD, USA: Agency for Healthcare Research and Quality; 2008. Available from: http:/www.guideline.gov/syntheses/synthesis aspx?id=38658. Accessed February 14, 2014.

42. Ensrud KE, Ewing SK, Taylor BC, et al. Comparison of 2 frailty indexes for prediction of falls, disability, fractures, and death in older women. Arch Intern Med. 2008;168:382-389.

43. Dempster DW. Osteoporosis and the burden of osteoporosis-related fractures. Am J Manag Care. 2011;117 Suppl 6:S164-S169.

44. National Institutes of Health Osteoporosis and Related Bone Diseases National Resource Center. Bone Mass Measurement: What the numbers mean. Jan 2012. Available from: http://www.niams.nih.gov/Health_Info/ Bone/Bone_Health/bone_mass_measure.asp. Accessed February 14, 2014.

45. Wall M, Lohfeld L, Giangregorio L, et al. Fracture risk assessment in long-term care: a survey of long-term care physicians. BMC Geriatr. 2013;13:109.

46. Mitchell PJ. Fracture Liaison Services: a systematic approach to secondary fracture prevention. Osteoporosis Review. 2009;17:14-16.

47. Giles M, Van Der Kallen J, Parker V, et al. A team approach: implementing a model of care for preventing osteoporosis related fractures. Osteoporos Int. 2011;22:2321-2328.

48. Eisman JA, Bogoch ER, Dell R, et al. Making the first fracture the last fracture: ASBMR Task Force report on secondary fracture prevention. J Bone Miner Res. 2012;27:1-8.

49. Ganda J, Puech M, Chen JS, et al. Models of care for the secondary prevention of osteoporotic fractures: a systematic review and metaanalysis. Osteoporos Int. 2013;24:393-406.

50. Nahm ES, Barker B, Resnick B, Covington B, Magaziner J, Brennan PF. Effects of a social cognitive theory-based hip fracture prevention web site for older adults. Comput Inform Nurs. 2010;28:371-379.

51. Qi BB, Resnick B, Smeltzer SC, Bausell B. Self-efficacy program to prevent osteoporosis among Chinese immigrants: a randomized controlled trial. Nurs Res. 2011;60:393-404.
52. Ryan P, Schlidt A, Ryan C. The impact of osteoporosis prevention programs on calcium intake: a systematic review. Osteoporos Int. 2013; 24:1791-1801.

53. Sujic R, Gignac MA, Cockerill R. A review of patient-centred postfracture interventions in the context of theories of health behaviour change. Osteoporos Int. 2011;22:2213-2224.

54. Lau AN, Ioannidis G, Potts Y, et al. What are the beliefs, attitudes and practices of front-line staff in long-term care (LTC) facilities related to osteoporosis awareness, management and fracture prevention? BMC Geriatr. 2010;10:73.

55. Lee LY, Lai EK. Osteoporosis in older Chinese men: knowledge and health beliefs. J Clin Nurs. 2006;15:353-355.

56. Sharts-Hopko NC, Sullivan MP. Beliefs, perceptions, and practices related to osteoporosis risk reduction among women with multiple sclerosis. Rehabil Nurs. 2002;27:232-236.

57. Smeltzer SC, Zimmerman V, Capriotti T. Osteoporosis risk and low bone mineral density in women with physical disabilities. Arch Phys Med Rehabil. 2005;86:582-586.

58. Endicott RD. Knowledge, health beliefs, and self-efficacy regarding osteoporosis in perimenopausal women. J Osteoporos. 2013;2013:853531.

59. Twiss JJ, Gross GJ, Waltman NL, Ott CD, Lindsey AM. Health behaviors in breast cancer survivors experiencing bone loss. J Am Acad Nurse Pract. 2006;18:471-481.

60. Chang SF. Knowledge, health beliefs and health-related behaviours of first-degree relatives of women suffering from osteoporosis in Taiwan: a questionnaire survey. J Clin Nurs. 2008;17:1280-1286.

61. Chang SF, Yang RS, Chung UL, Chen CM, Cheng MH. Perception of risk factors and DXA T score among at-risk females of osteoporosis. J Clin Nurs. 2010;19:1795-1802.

62. Sandison R, Gray M, Reid DM. Lifestyle factors for promoting bone health in older women. J Adv Nurs. 2004;45:603-610.

63. Besser SJ, Anderson JE, Weinman J. How do osteoporosis patients perceive their illness and treatment? Implications for clinical practice. Arch Osteoporos. 2012;7:115-124.

64. Brennan SL, Pasco JA, Urquhart DM, Oldenburg B, Hanna F, Wluka AE. The association between socioeconomic status and osteoporotic fracture in population-based adults: a systematic review. Osteoporos Int. 2009;20:1487-1497.

65. Navarro MC, Sosa M, Saavedra P, et al. Poverty is a risk factor for osteoporotic fractures. Osteoporos Int. 2009;20:393-398.

66. Drake MT, Khosla S. Male osteoporosis. Endocrinol Metab Clin North Am. 2012;41:629-641.

67. Templeton KJ. Commentary on: Male and non-English-speaking patients with fracture have poorer knowledge of osteoporosis. $J$ Bone Joint Surg Am. 2011;20;93:e43.

68. Amre H, Safadi R, Jarrah S, Al-Amer R, Froelicher ES. Jordanian nursing students' knowledge of osteoporosis. Int J Nurs Pract. 2008;14: 228-236.

69. Zhang YP, Li XM, Wang DL, Guo XY, Guo X. Evaluation of educational program on osteoporosis awareness and prevention among nurse students in China. Nurs Health Sci. 2012;14:74-80.

70. Lai PS, Chua SS, Chan SP. Impact of pharmaceutical care on knowledge, quality of life and satisfaction of postmenopausal women with osteoporosis. Int J Clin Pharm. 2013;35:629-637.

71. Solomon DH, Gleeson T, Iversen $\mathrm{M}$, et al. A blinded randomized controlled trial of motivational interviewing to improve adherence with osteoporosis medications: design of the OPTIMA trial. Osteoporos Int. 2010;21:137-144.

72. Haynes RB, Ackloo E, Sahota N, McDonald HP, Yao X. Interventions for enhancing medication adherence. Cochrane Database Syst Rev. 2008;2:CD000011.

73. Gleeson T, Iversen MD, Avorn J, et al. Interventions to improve adherence and persistence with osteoporosis medications: a systematic literature review. Osteoporos Int. 2009;20:2127-2134.

74. Shanthi Johnson CS, McLeod W, Kennedy L, McLeod K. Osteoporosis health beliefs among younger and older men and women. Health Educ Behav. 2008;35:721-733. 
75. McLeod KM, Johnson CS. A systematic review of osteoporosis health beliefs in adult men and women. J Osteoporos. 2011;2011:197454.

76. Resnick B, Jenkins LS. Testing the reliability and validity of the selfefficacy for exercise scale. Nurs Res. 2000;49:154-159.

77. Resnick B, Gruber-Baldini AL, Galik E, et al. Changing the philosophy of care in long-term care: testing of the restorative care intervention. Gerontologist. 2009;49:175-184.

78. Resnick B, Wehren L, Orwig D. Reliability and validity of the selfefficacy and outcome expectations for osteoporosis medication adherence scales. Orthop Nurs. 2003;22:139-147.

79. Bhurosy T, Jeewon R. Effectiveness of a theory-driven nutritional education program in improving calcium intake among older Mauritian adults. Scientific World Journal. 2013;2013:750128.

80. Ha M, Hu J, Petrini MA, McCoy TP. The effects of an educational self efficacy intervention on osteoporosis prevention and diabetes self-management among adults with type 2 diabetes mellitus. Biol Res Nurs. January 10, 2014. [Epub ahead of print.]

81. Plawecki K, Chapman-Novakofski K. Effectiveness of community intervention in improving bone health behaviors in older adults. $J$ Nutr Gerontol Geriatr. 2013;32:145-160.

82. Chan MF, Kwong WS, Zang YL, Wan PY. Evaluation of an osteoporosis prevention education programme for young adults. $J$ Adv Nurs. 2007;57:270-285.

83. Chan MF, Ko CY, Day MC. The effectiveness of an osteoporosis prevention education programme for women in Hong Kong: a randomized controlled trial. J Clin Nurs. 2005;14:1112-1123.

84. Chan MF, Ko CY. Osteoporosis prevention education programme for women. $J A d v$ Nurs. 2006;54:159-170.

85. Ryan P, Maierle D, Csuka ME, Thomson A, Szabo A. Computer-based intervention to enhance self-management of calcium and vitamin $\mathrm{D}$ in women. West J Nurs Res. 2013;35:986-1010.

86. Sedlak CA, Doheny MO, Jones SL. Osteoporosis education programs: changing knowledge and behaviors. Public Health Nurs. 2000; $17: 398-402$.

87. Sedlak CA, Doheny MO, Estok PJ, Zeller RA, Winchell J. DXA, health beliefs, and osteoporosis prevention behaviors. J Aging Health. 2007;19:742-756.

88. Silverman S, Gold DT. Compliance and persistence with osteoporosis medications: a critical review of the literature. Rev Endocr Metab Disord. 2010;11:275-280.

89. Rizzoli R, Abraham C, Brandi ML. Nutrition and bone health: turning knowledge and beliefs into healthy behaviour. Curr Med Res Opin. 2014;30(1):131-141.

90. Dheny MO, Sedlak CA, Hall RJ, Estok PJ. Structural model for osteoporosis preventing behavior in men. Am J Mens Health. 2010;4: 334-343.

91. Mauck KF, Clarke BL. Diagnosis, screening, prevention, and treatment of osteoporosis. Mayo Clin Proc. 2006;81:662-672.

92. Pollycove R, Simon JA. Osteoporosis: screening and treatment in women. Clin Obstet Gynecol. 2012;55:681-691.

93. Lems WF, den Heijer M. Established and forthcoming drugs for the treatment of osteoporosis. Neth J Med. 2013;71(4):188-193.

94. Suresh E, Pazianas M, Abrahamsen B. Safety issues with bisphosphonate therapy for osteoporosis. Rheumatology (Oxford). 2014;53(1):19-31.

95. Chen HV. Bisphosphonate-associated osteonecrosis of the jaw: patient care considerations: overview for the orthopaedic nursing healthcare professional. Orthop Nurs. 2010;29:176-180.

96. Hodges LA, Connolly SM, Winter J, et al. Modulation of gastric $\mathrm{pH}$ by a buffered soluble effervescent formulation: a possible means of improving gastric tolerability of alendronate. Int J Pharm. 2012;432: $57-62$.

97. Sedghizadeh PP, Stanley K, Caligiuri M, Hofkes S, Lowry B, Shyler CF. Oral bisphosphonate use and the prevalence of osteonecrosis of the jaw: an institutional inquiry. J Am Dent Assoc. 2009;140:61-66.

98. Ragucci KR, Shrader SP. Osteoporosis treatment: an evidence-based approach. J Gerontol Nurs. 2011;37:17-22.
99. Boonen S, Adachi JD, Man Z, et al. Treatment with denosumab reduces the incidence of new vertebral and hip fractures in postmenopausal women at high risk. J Clin Endocrinol Metab. 2011;96:1727-1736.

100. Papapoulos S, Chapurlat R, Libanati C, et al. Five years of denosumab exposure in women with postmenopausal osteoporosis: results from the first two years of the FREEDOM extension. $J$ Bone Miner Res. 2012;27:694-701.

101. Cummings SR, San Martin J, McClung MR, et al. Denosumab for prevention of fractures in postmenopausal women with osteoporosis. N Engl J Med. 2009;361:756-765.

102. Delmas PD, Genant HK, Crans GG, et al. Severity of prevalent vertebral fractures and the risk of subsequent vertebral and nonvertebral fractures: results from the MORE trial. Bone. 2003;33:522-532.

103. Vogel VG, Costantino JP, Wickerham DL, et al. Effects of tamoxifen vs raloxifene on the risk of developing invasive breast cancer and other disease outcomes: the NSABP Study of Tamoxifen and Raloxifene (STAR) P-2 trial. JAMA. 2006;295:2727-2741.

104. Ljunggren Ö, Barrett A, Stoykov I, et al. Effective osteoporosis treatment with teriparatide is associated with enhanced quality of life in postmenopausal women with osteoporosis: the European Forsteo Observational Study. BMC Musculoskelet Disord. 2013;14:251.

105. Cranney A, Tugwell P, Zytaruk N, et al. Meta-analyses of therapies for postmenopausal osteoporosis. VI. Meta-analysis of calcitonin for the treatment of postmenopausal osteoporosis. Endocr Rev. 2002;23:540-551.

106. National Osteoporosis Foundation. FDA panel votes to remove longused osteoporosis drug over cancer risk. March 13, 2013. Available from: http://nof.org/news/944. Accessed February 4, 2014.

107. Martyn-St James M, Carroll S. A meta-analysis of impact exercise on postmenopausal bone loss: the case for mixed loading exercise programmes. Br J Sports Med. 2009;43:898-908.

108. Martyn-St James M, Carroll S. Effects of different impact exercise modalities on bone mineral density in premenopausal women: a metaanalysis. J Bone Miner Metab. 2010;28:251-267.

109. de Kam D, Smulders E, Weerdesteyn V, Smits-Engelsman BC. Exercise interventions to reduce fall-related fractures and their risk factors in individuals with low bone density: a systematic review of randomized controlled trials. Osteoporos Int. 2009;20: 2111-2125.

110. Sinaki M, Pfeifer M, Preisinger E, et al. The role of exercise in the treatment of osteoporosis. Curr Osteoporos Rep. 2010;8:138-144.

111. Bischoff-Ferrari HA, Dawson-Hughes B, Staehelin HB, et al. Fall prevention with supplemental and active forms of vitamin D: a metaanalysis of randomised controlled trials. BMJ. 2009;339:b3692.

112. Smith ML, Ory MG, Ahn S, Bazzarre TL, Resnick B. Older adults' participation in a community-based falls prevention exercise program: relationships between the EASY tool, program attendance, and health outcomes. Gerontologist. 2011;51:809-821.

113. Institute of Medicine. Consensus report: Dietary reference intakes for calcium and vitamin D. November 30, 2010. Available from: http:// www.iom.edu/Reports/2010/Dietary-Reference-Intakes-for-Calciumand-Vitamin-D.aspx. Accessed February 14, 2014.

114. Gammage KL, Francoeur C, Mack DE, Klentrou P. Osteoporosis health beliefs and knowledge in college students: the role of dietary retraining. Eat Behav. 2009;10:65-67.

115. Gammage KL, Klentrou P. Predicting osteoporosis prevention behaviors: health beliefs and knowledge. Am J Health Behav. 2011;35:371-382.

116. Francis KL, Matthews BL, Van Mechelen W, Bennell KL, Osborne RH. Effectiveness of a community-based osteoporosis education and self-management course: a wait list controlled trial. Osteoporos Int. 2009;20:1563-1570.

117. Laslett LL, Lynch J, Sullivan TR, McNeil JD. Osteoporosis education improves osteoporosis knowledge and dietary calcium: comparison of a 4-week and a one-session education course. Int J Rheum Dis. 2011;14:239-247. 
118. Drieling RL, Ma J, Thiyagarajan S, Stafford RS. An Internet-based osteoporotic fracture risk program: effect on knowledge, attitudes, and behaviors. J Womens Health (Larchmt). 2011;20:1895-1907.

119. Gaines JM, Marx KA. Older men's knowledge about osteoporosis and educational interventions to increase osteoporosis knowledge in older men: a systematic review. Maturitas. 2011;68:5-12.

120. Babatunde OT, Himburg SP, Newman FL, Campa A, Dixon Z. Theorydriven intervention improves calcium intake, osteoporosis knowledge, and self-efficacy in community-dwelling older Black adults. J Nutr Educ Behav. 2011;43:434-440.
121. Darling AL, Millward DJ, Torgerson DJ, Hewitt CE, Lanham-New SA. Dietary protein and bone health: a systematic review and metaanalysis. Am J Clin Nutr. 2009;90:1674-1692.

122. Kanis JA, McCloskey EV, Johansson H, et al. European guidance for the diagnosis and management of osteoporosis in postmenopausal women. Osteoporos Int. 2013;24:23-57.

Nursing: Research and Reviews

\section{Publish your work in this journal}

Nursing: Research and Reviews is an international, peer-reviewed, open access journal publishing original research, reports, reviews and commentaries on all aspects of nursing and patient care. These include patient education and counselling, ethics, management and organizational issues, diagnostics and prescribing, economics and

\section{Dovepress}

resource management, health outcomes, and improving patient safety in all settings. The manuscript management system is completely online and includes a very quick and fair peer-review system. Visit http://www.dovepress.com/testimonials.php to read real quotes from published authors.

Submit your manuscript here: http://www.dovepress.com/nursing-research-and-reviews-journal 